\title{
Phenotypic Diversity among Ruminal Isolates of Prevotella ruminicola: Proposal of Prevotella brevis sp. nov., Prevotella bryantii sp. nov., and Prevotella albensis sp. nov. and Redefinition of Prevotella ruminicola
}

\author{
GORAZD AVGUŠTIN, ${ }^{1}$ R. JOHN WALLACE, ${ }^{2}$ AND HARRY J. FLINT ${ }^{2 *}$ \\ Zootechnical Department, Biotechnical Faculty, University of Ljubljana, 1230 Domzale, Slovenia, ${ }^{1}$ \\ and Rowett Research Institute, Bucksburn, Aberdeen AB21 9SB, United Kingdom ${ }^{2}$
}

\begin{abstract}
Selected phenotypic characteristics of isolates of Prevotella ruminicola (formerly Bacteroides ruminicola) were studied in order to establish whether the characteristics of genotypic strain groups established previously on the basis of 16S ribosomal DNA sequences differed systematically. Among strains formerly considered $P$. ruminicola subsp. brevis, strains related to strain $\mathrm{GA33}^{\mathrm{T}}$ ( $\mathrm{T}=$ type strain) typically failed to produce carboxymethyl cellulase (CMCase) activity detectable by plate assays and failed to ferment xylose, while strains related to strain $B_{1} 4^{T}$ produced abundant CMCase and fermented xylose. We propose that strains related to $\mathrm{GAB3}^{\mathrm{T}}$, which have DNA G+C contents between 45 and $51 \mathrm{~mol} \%$, should be assigned to a new species, Prevotella brevis, and that strains related to $B_{1} 4^{\mathrm{T}}$, which have DNA $G+C$ contents between 39 and $43 \mathrm{~mol} \%$, should be assigned to another new species, Prevotella bryantii. Most of the isolates formerly classified as $P$. ruminicola subsp. ruminicola strains produced CMCase and had DNA G+C contents between 45 and $51 \mathrm{~mol} \%$, and we propose that these organisms should be placed in the redefined species $P$. ruminicola. A small group of isolates that have lower $G+C$ contents are assigned to another new species, Prevotella albensis. Most $P$. brevis and $P$. bryantii strains produced abundant extracellular DNase activity. Proteinase activities (as determined by $\left[{ }^{14} \mathrm{C}\right]$ casein hydrolysis) varied widely between strains, and $P$. brevis strains exhibited the highest mean activity. All strains produced dipeptidyl peptidase activity, but the relative activities against different peptide substrates exhibited by $\boldsymbol{P}$. bryantii, $\boldsymbol{P}$. albensis, and $\boldsymbol{P}$. brevis differed systematically. The phenotypic differences among the newly defined species suggest that they may occupy distinct niches within the rumen ecosystem.
\end{abstract}

Bacteria currently classified as Prevotella ruminicola (formerly Bacteroides ruminicola) constitute one of the most numerous groups recovered from the rumen and from regions of the hindgut of many mammalian species $(4,12,13,18,19,22$, 25). Many strains have activities that suggest that they play important roles in the utilization of polysaccharides of plant origin, including xylans, pectins, and starch $(6,7,14)$, and in the metabolism of peptides and proteins $(17,21,26,28)$. There is now abundant evidence from partial 16S ribosomal DNA (rDNA) sequence, DNA-DNA hybridization, and total-protein sodium dodecyl sulfate-polyacrylamide gel electrophoresis analyses that strains currently classified as $P$. ruminicola can be extremely diverse at the genotypic level $(2,15,16)$. Formal reclassification into new species was deferred previously for several reasons. Mannarelli et al. (15) were able to form a coherent group of strains related to the type strain of $P$. $r u$ minicola, strain 23, from DNA hybridization and DNA base composition data, but were unable to group any of the remaining strains that they studied, which included $P$. ruminicola subsp. brevis type strain GA33, on the basis of these criteria. On the basis of 16S rDNA sequences and PCR amplification data obtained with diagnostic sequences, Avguštin et al. (2) were able to identify three groups of rumen strains related to strains $23^{\mathrm{T}}\left(\mathrm{T}=\right.$ type strain), GA33 ${ }^{\mathrm{T}}$, and $\mathrm{B}_{1} 4^{\mathrm{T}}$ which were considered the basis for new species, but it was felt that reclassification should await the demonstration of phenotypic differences. Here we report the results of an investigation of phe-

* Corresponding author. Mailing address: Rowett Research Institute, Greenburn Road, Bucksburn, Aberdeen AB21 9SB, United Kingdom. Phone: (0) 1224 716651. Fax: (0) 1224 716687. E-mail: h.flint@rri sari.ac.uk. notypic differences among these three groups and a fourth strain group recognized from a study of additional strains. As a result of our findings, we propose a reclassification which we hope will facilitate future physiological, ecological, and genetic work on this important group of strictly anaerobic bacteria.

\section{MATERIALS AND METHODS}

Strains. The origins of the bacterial strains have been described previously ( 2 16). Strains were grown anaerobically at $38^{\circ} \mathrm{C}$ in $\mathrm{M} 2 \mathrm{GSC}$ medium (the liquid form of medium 2 of Hobson [11] modified to contain $30 \%$ rumen fluid and $0.2 \%$ soluble starch, as well as $0.2 \%$ cellobiose and $0.2 \%$ glucose as energy sources) which was prepared anaerobically under $\mathrm{O}_{2}$-free $\mathrm{CO}_{2}$ (3). Medium containing $0.2 \%$ glucose as the only added energy source is referred to below as M2G medium.

DNA G+C contents. Chromosomal DNAs were extracted from strains 52/3 and $79 / 1$ and their melting temperatures were determined as described previously (2).

DNase activities. Cultures were grown at $38^{\circ} \mathrm{C}$ to the stationary phase and were centrifuged for $15 \mathrm{~min}$ at $2,000 \times g$. Nonmethylated $\lambda$ phage DNA $(\lambda \mathrm{C} 1857$ Sam 7 propagated in dam dcm Escherichia coli GM119; catalog no. D-3654; Sigma) or circular plasmid pBR322 DNA (host, E. coli HB101; Pharmacia) was added to samples of culture supernatant at a final concentration of $5 \mu \mathrm{g} / \mathrm{ml}$, and this was followed by incubation for $30 \mathrm{~s}$ or $10 \mathrm{~min}$ at $30^{\circ} \mathrm{C}$. Reactions were terminated by extraction with an equal volume of a $50: 50(\mathrm{vol} / \mathrm{vol})$ mixture of Tris-equilibrated phenol (pH 7.4) and chloroform, and samples of the aqueous phase were analyzed by electrophoresis in $0.6 \%(\mathrm{wt} / \mathrm{vol})$ agarose gels (8). A positive reaction was a reaction in which the detectable intact DNA disappeared within $10 \mathrm{~min}$. The results of these assays corresponded with the results obtained when clear zone formation around colonies grown on M2GSC agar plates containing $2 \mathrm{mg}$ of herring sperm DNA per $\mathrm{ml}(20)$ was examined.

Substrate fermentation tests. Cells were grown to the late exponential phase in M2GSC broth media, recovered by centrifugation at $3,000 \times \mathrm{g}$ for $10 \mathrm{~min}$, and resuspended anaerobically in the same medium without sugars or resazurin but with $0.017 \%$ (wt $/ \mathrm{vol}$ ) bromocresol purple as a $\mathrm{pH}$ indicator. API $50 \mathrm{CH}$ strips (API System S.A., Lyon, France) were inoculated by using the manufacturer's recommended methods and were incubated in an anaerobic glove box (Scholzen Technik, Kriens, Switzerland) at $38^{\circ} \mathrm{C}$ under a $100 \% \mathrm{CO}_{2}$ atmosphere. The strips were read after $6,24,48$, and $72 \mathrm{~h}$. Strains were also analyzed for growth (optical 
TABLE 1. Characteristics of proposed rumen Prevotella spp.

\begin{tabular}{|c|c|c|c|c|}
\hline Characteristic & P. bryantii & P. brevis & P. albensis & $P$. ruminicola \\
\hline DNA $\mathrm{G}+\mathrm{C}$ content $(\mathrm{mol} \%)$ & $39.2-42.1[4]^{a}$ & $45.3-50.6[5]$ & $39.4-43.8[3]$ & $46.5-50.6[13]$ \\
\hline CMCase & $+{ }^{w(3)}[6]^{b}$ & $-[6]$ & $w^{-(1)}[3]$ & $+[16]$ \\
\hline Xylanase & $+/ w^{-(3)}[6]$ & $-[6]$ & $-[3]$ & $+{ }^{w}(6)[16]$ \\
\hline Amylase & $+[6]$ & $+[6]$ & $+^{-(1)}[3]$ & $+[16]$ \\
\hline DNase & $+^{-(1)}[4]$ & $+^{w(1)}[6]$ & $-[3]$ & $-{ }^{+(2)}[15]$ \\
\hline \multicolumn{5}{|l|}{ Fermentation of (API tests) ${ }^{c}$ : } \\
\hline D-Xylose & $+[6]$ & $-[4]$ & $+[3]$ & $+^{-(2)}[10]$ \\
\hline D-Mannose & $+[6]$ & $+[4]$ & $-{ }^{+(1)}[3]$ & $+^{-(1)}[10]$ \\
\hline Arbutin & $+[6]$ & $-[4]$ & $+[3]$ & $+^{-(1)}[10]$ \\
\hline Salicin & $+[6]$ & $-[4]$ & $+[3]$ & $+^{-(2)}[10]$ \\
\hline Melibiose & $+{ }^{-(2)}[6]$ & $+[4]$ & $-[3]$ & $+^{-(2)}[10]$ \\
\hline Sucrose & $+[6]$ & $+[4]$ & $-{ }^{+}(1)[3]$ & $+[10]$ \\
\hline Inulin & $+[6]$ & $+[4]$ & $-[3]$ & $+^{-(3)}[10]$ \\
\hline Acetylglucosamine & $-[6]$ & $+{ }^{w}(2)[4]$ & $-[3]$ & $-/ w^{+(5)}[10]$ \\
\hline D-Raffinose & $+[6]$ & $+[4]$ & $-{ }^{+(1)}[3]$ & $+^{-(1)}[10]$ \\
\hline$\beta$-Gentobiose & $-{ }^{+(1)}[6]$ & $+[4]$ & $+[3]$ & $+/ w^{-(3)}[10]$ \\
\hline Rhamnose & $+{ }^{w(3)}[6]$ & $-[4]$ & $-[3]$ & $-/ w^{+(1)}[10]$ \\
\hline \multicolumn{5}{|c|}{ Fermentation of (growth in $\mathrm{M} 2$ medium) ${ }^{d}$ : } \\
\hline Xylose & $+[6]$ & $-[6]$ & $+[3]$ & $+/ w^{-(4)}[11]$ \\
\hline Inulin & $+[6]$ & $-/ w^{+(2)}[6]$ & $-[3]$ & $+/ w^{-(5)}[11]$ \\
\hline Salicin & $+[6]$ & $-[6]$ & $+[3]$ & $+/ w^{-(1)}[11]$ \\
\hline Gum arabic & $-{ }^{+(3)}[6]$ & $++^{-(2)}[6]$ & $-[3]$ & $-^{+/ w(2)}[11]$ \\
\hline
\end{tabular}

${ }^{a}$ The numbers in brackets are the numbers of strains examined. The strains examined were the strains listed in Table 2 and $P$. bryantii $92 / 1$. The $P$. brevis-like and

$P$. ruminicola-like isolates were included with the $P$. brevis and $P$. ruminicola isolates, respectively.

${ }^{b}+$, positive reaction; - , negative reaction; w, weak reaction; $-/$ w, negative or weak reaction. The superscripts indicate the less common reaction and the numbe of strains that exhibit that reaction (in parentheses).

${ }^{c}$ All strains fermented D-glucose, D-fructose, galactose, L-arabinose, esculin, cellobiose, and lactose. None of the strains fermented glycerol, erythritol, adonitol, L-sorbose, dulcitol, inositol, mannitol, sorbitol, trehalose, xylitol, L-xylose, $\beta$-methyl-xyloside, D-lyxose, D-fucose, D-arabitol, 2-keto-gluconate, or 5-keto-gluconate.

${ }^{d}$ A positive reaction was a reaction in which the change in the $\mathrm{OD}_{650}$ was greater than $0.5 \mathrm{U}$ or the reduction in culture pH was greater than $0.5 \mathrm{U}$ compared with basal media that contained no added energy source and were inoculated simultaneously. A weak reaction was a reaction in which the change in $\mathrm{OD}$ (50 or $\mathrm{pH}$ was between 0.2 and $0.5 \mathrm{U}$. Some cultures exhibited significant changes in $\mathrm{OD}_{650}$ but no significant change in pH (e.g., five of the six $P$. bryantii strains when grown with xylose), while other cultures exhibited changes in $\mathrm{pH}$ but no significant increases in $\mathrm{OD}_{650}$.

density at $\left.650 \mathrm{~nm}\left[\mathrm{OD}_{650}\right]\right)$ and for changes in the culture $\mathrm{pH}$ following inoculation of basal $\mathrm{M} 2$ broth media containing a selection of single substrates $(0.2 \%$, wt/vol). The tubes were compared with tubes containing basal M2 medium inoculated simultaneously.

Polysaccharide degradation tests on agar plates. To detect polysaccharidase activities, plates were prepared containing $1 \%$ (wt/vol) Bacto Agar (Difco) and $0.2 \%$ carboxymethyl cellulose (CMC) (catalog no. C-4888; Sigma), $0.2 \%$ oat spelt xylan (catalog no. X-0627; Sigma), or $2.0 \%$ maize starch (catalog no. D-5751; Sigma) in $50 \mathrm{mM}$ sodium phosphate buffer ( $\mathrm{pH} 6.5$ ) containing $1 \mathrm{mM}$ DL-dithiothreitol (DTT). The same strain differences were observed whether the plates were prepared and incubated aerobically or were prepared anaerobically and incubated in a Coy anaerobic cabinet in an atmosphere containing $55 \% \mathrm{CO}_{2}$, $40 \% \mathrm{~N}_{2}$, and $5 \% \mathrm{H}_{2}$. Portions $(3 \mu \mathrm{l})$ of a freshly harvested culture that had been grown for $24 \mathrm{~h}$ in M2GSC medium were spotted on the surfaces of the agar plates. After $16 \mathrm{~h}$ of incubation at $38^{\circ} \mathrm{C}, \mathrm{CMC}$ hydrolysis and xylan hydrolysis were visualized by staining with Congo red (23), and starch degradation was visualized by staining for 5 min with $5 \times$-diluted Gram's iodine.

Casein hydrolysis. $\left[{ }^{14} \mathrm{C}\right.$ casein hydrolysis $(26)$ was determined by using samples from cultures grown for $40 \mathrm{~h}$ in M2G medium. Incubations were performed anaerobically for $2 \mathrm{~h}$ at $38^{\circ} \mathrm{C}$ before addition of trichloroacetic acid to a concentration of $5 \%(\mathrm{wt} / \mathrm{vol})$ and centrifugation at $13,400 \times g$ for $3 \mathrm{~min}$. Solubilized radioactivity was determined from the supernatant by liquid scintillation counting with a model 1900 CA Tri-Carb instrument (Packard).

Screening cultures for peptidase activities. Overnight cultures were harvested by centrifugation at $27,500 \times g$ for $15 \mathrm{~min}$ at $4^{\circ} \mathrm{C}$. The pellets were washed once with anaerobic $25 \mathrm{mM}$ potassium phosphate $(\mathrm{pH} 7.0)$ and resuspended to onehalf the original volume in the same buffer. Activity against $\mathrm{Ala}_{2}-p$-nitroanilide ( $\mathrm{Ala}_{2}$-pNA) was determined in continuous assays by using a plate reader fitted with a 420-nm filter. Each assay mixture contained $100 \mu \mathrm{l}$ of $4 \mathrm{mM} \mathrm{Ala}_{2}$-pNA dissolved in anaerobic $25 \mathrm{mM}$ potassium phosphate buffer $(\mathrm{pH} 7.0), 50 \mu$ of DTT, and $50 \mu \mathrm{l}$ of washed cell suspension, and the rate of reaction at $39^{\circ} \mathrm{C}$ was calculated from the initial rate of release of $p$-nitroanilide. A continuous fluorimetric assay was carried out with 4-methoxynaphthylamide (MNA) substrates by using a fluorimetric plate reader equipped with a $365-\mathrm{nm}$ excitation filter and a 450 -nm emission filter. Most of the assay mixtures contained $20 \mu \mathrm{l}$ of a $2.5 \mathrm{mM}$ substrate solution dissolved in buffer. The only exception was the assay mixture for Leu Val-MNA, which was dissolved in ethanol; this mixture contained $50 \mu \mathrm{l}$ of $4 \mathrm{mM}$ DTT, $80 \mu \mathrm{l}$ of water, and $50 \mu \mathrm{l}$ of cell suspension or extract. The plates were incubated and the rates of hydrolysis were calculated as described above for $\mathrm{Ala}_{2}$-pNA hydrolysis. All centrifugations and transfers were carried out under
$\mathrm{CO}_{2}$. Protein contents were determined by using the Folin reagent with bovine serum albumin as the standard.

\section{RESULTS AND DISCUSSION}

Genotypic variation. Thirty-one isolates formerly considered $P$. ruminicola strains were included in this study. These strains included 27 of the 29 isolates previously studied by Avguštin et al. (2). The two strains omitted were strain TC20, which was not recognized by a Bacteroides-Prevotella-specific oligonucleotide, and strain NCFB 2202, which on the basis of recent evidence from 16S rRNA profiling (30) is more closely related to Bacteroides spp. than to the genus Prevotella. In addition, strains $92 / 1$ and $92 / 2$, which resemble $B_{1} 4^{T}$, and strains $52 / 3$ and $79 / 1$, which resemble $M 384^{\mathrm{T}}$ in their total-protein sodium dodecyl sulfate-polyacrylamide gel electrophoresis patterns (16), were also included. Of the 31 strains studied, 12 are recognized by an oligonucleotide specific for the strain $23^{\mathrm{T}}$ group of strains, 6 (including 92/1 and 92/2) are recognized by an oligonucleotide specific for strains related to $B_{1} 4^{\mathrm{T}}$, and 4 are recognized by an oligonucleotide specific for strains related to $\mathrm{GA} 33^{\mathrm{T}}$, as reported previously (2). In addition, strains $52 / 3$ and $79 / 1$ are recognized by an oligonucleotide designed to recognize strains related to $\mathrm{M} 384^{\mathbf{T}}$ (1). For clarity, below we refer to isolates related to strain $23^{\mathrm{T}}$ as $P$. ruminicola (redefined), isolates related to strain $\mathrm{GA} 33^{\mathrm{T}}$ as Prevotella brevis $\mathrm{sp}$. nov., isolates related to strain $\mathrm{B}_{1} 4^{\mathrm{T}}$ as Prevotella bryantii $\mathrm{sp}$. nov., and isolates related to strain $\mathrm{M} 384^{\mathrm{T}}$ as Prevotella albensis sp. nov. DNA $\mathrm{G}+\mathrm{C}$ values are summarized in Table 1 . The values for strains $52 / 3(39.7 \mathrm{~mol} \%)$ and $79 / 1(39.4 \mathrm{~mol} \%)$ were determined in this study; the values for other strains were from previous determinations (2). Table 1 shows that the DNA 
$\mathrm{G}+\mathrm{C}$ contents of $P$. bryantii and $P$. albensis strains are significantly lower than the DNA G+C contents of $P$. brevis and $P$. ruminicola strains.

Six of the isolates, which have $\mathrm{G}+\mathrm{C}$ contents between 45 and $51 \mathrm{~mol} \%$, were not recognized by any of the four specific oligonucleotides and differ significantly in their 16S rDNA sequences from the other strains (2). On the basis of their phenotypic characteristics four of these strains (223/M2/7, TF2-5, TC2-28, and TC2-24) are described below as P. ruminicola-like and two (9958/78 and TS2-7) are described as $P$. brevis-like.

Polysaccharidase activities. Strains were screened for the ability to form clear zones when cultures were spotted onto agar containing oat spelt xylan, CMC, or starch (Table 1). All of the strains except M $384^{\mathrm{T}}$ gave clear zones (diameter, $>5$ $\mathrm{mm}$ ) on plates containing starch. All $16 P$. ruminicola strains (strains related to $23^{\mathrm{T}}$ ) gave clear zones on plates containing CMC and xylan. All six $P$. bryantii strains (strains related to $\mathrm{B}_{1} 4^{\mathrm{T}}$ ) gave clear zones with $\mathrm{CMC}$, although three gave no obvious clear zones with xylan. The carboxymethyl cellulase (CMCase) test may be the most reliable test since it has been suggested that much of the xylanase activity in Prevotella sp. is intracellular (10), while more of the CMCase may be expressed on the cell surface (9). The group of strains related to GA33 ${ }^{\mathrm{T}}$ (P. brevis) was distinguished by a failure to give clear zones on xylan- or CMC-containing plates, while the three $P$. albensis strains gave weak or no clear zones (Table 1).

Substrate utilization patterns. The substrate fermentation reactions of 23 strains were tested by using API 50CH and API $20 \mathrm{~A}$ test kits. Clear results were not always obtained with API $20 \mathrm{~A}$ kits, in part because of decolorization, and the results given in Table 1 are based on API 50CH tests. Clear differences were found between $P$. brevis and $P$. bryantii strains, with $P$. brevis showing negative reactions for xylose, arbutin, and salicin and a positive reaction for $\mathrm{N}$-acetylglucosamine. Fermentation reactions for xylose, inulin, salicin, and gum arabic were also assessed by examining growth and $\mathrm{pH}$ changes in medium 2 (Table 1). Four $P$. brevis strains were the only strains to exhibit significant growth on gum arabic, although the two $P$. brevis-like strains failed to grow and some strains of other species gave significant $\mathrm{pH}$ changes. The failure of $P$. brevis strains to ferment arbutin or salicin contrasts with the finding of Bryant et al. (4) that GA33 ${ }^{\mathrm{T}}$ fermented salicin. It seems possible that this characteristic of $\mathrm{GA} 33^{\mathrm{T}}$ could have changed since it was first examined. The fermentation patterns obtained for $P$. albensis suggested that strains of this species may fail to ferment sugars (such as mannose, sucrose, and melibiose) that are fermented by most strains of the other species. $P$. ruminicola strains showed quite variable fermentation reactions.

DNase activities. Production of extracellular DNase activity is considered an attribute of strains presently classified as $P$. ruminicola subsp. brevis $(13,20)$. DNase activity released into culture supernatants during growth was assessed by a simple gel assay described previously (8) and by the formation of clearing zones in agar plates containing DNA. P. brevis and all of the $P$. bryantii strains except one (TC1-1) showed particularly high extracellular DNase activity, while only two of the $P$. ruminicola strains examined showed similarly high levels of DNase activity (Table 1$)$.

Peptidase and proteinase activities. Prevotella strains have an important role in protein and peptide metabolism in the rumen. The protease activities are similar in their properties to the activities of the mixed rumen population (26). All of the strains examined exhibited hydrolytic activity against ${ }^{14} \mathrm{C}$-labelled casein (Table 2), although the specific activity varied widely between strains. There was no strong correlation with the proposed new species, although $P$. brevis strains all exhibited high activities. Dipeptidyl peptidase appears to be the predominant mechanism of catabolic peptide metabolism in the mixed rumen population $(27,29)$, and Prevotella strains are the main bacteria that possess dipeptidyl peptidase activities $(16,28)$. Several dipeptidyl peptidase activities were present in all of the strains (Table 2). $P$. ruminicola strains showed no consistent pattern, but $P$. brevis strains tended to exhibit high levels of activity against GlyPro-MNA and LysAla-MNA and low levels of activity against GlyArg-MNA, while $P$. albensis exhibited high levels of activity against GlyArg-MNA and ArgArg-MNA. P. bryantii exhibited lower levels of activity against all substrates than $P$. albensis, particularly ArgArgMNA. Thus, the peptidase activities of Prevotella strains can be useful in confirming identification by the phenotypic characteristics described in Table 1.

Conclusions. The phenotypic differences in substrate utilization and polysaccharidase activities among the four strain groups related to strains $23^{\mathrm{T}}, \mathrm{GA} 33^{\mathrm{T}}, \mathrm{B}_{1} 4^{\mathrm{T}}$, and $\mathrm{M} 384^{\mathrm{T}}$, which were previously shown to differ genotypically, justify separation of these groups into the new species defined below. While there is evidence that 6 of the 31 strains studied show significant genetic divergence from the type strains of the four species and could conceivably warrant separate species status in the future, such status is not proposed at present because of the lack of additional related strains and the lack of convenient distinguishing tests. For this reason these strains are described as $P$. ruminicola-like or $P$. brevis-like on the basis of their phenotypic characteristics (Tables 1 and 2).

Emended description of Prevotella ruminicola. A complete description of Prevotella ruminicola subsp. ruminicola (formerly Bacteroides ruminicola subsp. ruminicola) biovar 1 (which includes type strain 23 [ = ATCC 19189]) was given by Holdeman et al. (13). Here $P$. ruminicola is redefined more narrowly to include only those strains that have DNA G+C contents between 45 and 52 mol\%. Most strains produce clear zones, which are visible after staining with Congo red, when stationary-phase cultures are spotted onto agar plates containing CMC. Most strains produce little or no detectable extracellular DNase. Most strains ferment arbutin, salicin, D-raffinose, Dmannose, sucrose, and melibiose. The type strain of this species is strain 23 (= ATCC 19189), which was the type strain of $P$. ruminicola subsp. ruminicola. All of the strains studied previously have a strict requirement for heme for growth in the absence of rumen fluid $(4,5,13)$.

Description of Prevotella albensis sp. nov. Prevotella albensis (al.ben'sis. M. L. adj: albensis, referring to Alba, the ancient name for Scotland north of the Forth and Clyde, where the type strain was isolated). A complete description of Prevotella ruminicola subsp. ruminicola (formerly Bacteroides ruminicola subsp. ruminicola) biovar 7 (to which type strain M384 shows the closest physiological resemblance) was given by Holdeman et al. (13). This new species includes a group of strains that have DNA $\mathrm{G}+\mathrm{C}$ contents between 39 and 43 mol\% and show weak or no CMCase activity in plate tests. Strains may fail to ferment melibiose, sucrose, D-mannose, $N$-acetylglucosamine, D-raffinose, or inulin, but most strains ferment xylose. Heme stimulates the growth of $\mathrm{M} 384^{\mathrm{T}}$ on media lacking rumen fluid $(24,26)$. The type strain is M384 (= DSM 11370).

Description of Prevotella brevis sp. nov. Prevotella brevis (bre'vis. L. adj. brevis, short). A complete description of Prevotella ruminicola subsp. brevis (formerly Bacteroides ruminicola subsp. brevis) biovars 1 and 2 (which include type strain GA33 [= ATCC 19188]) was given by Holdeman et al. (13). This new species includes only those strains resembling strain GA $33^{T}$ that have DNA $\mathrm{G}+\mathrm{C}$ contents between 45 and 52 
TABLE 2. Proteinase and dipeptidyi peptidase activities of rumen Prevotella isolates ${ }^{a}$

\begin{tabular}{|c|c|c|c|c|c|c|c|c|}
\hline \multirow{2}{*}{ Taxon } & \multirow{2}{*}{ Strain } & \multirow{2}{*}{$\begin{array}{c}\% \text { of }\left[{ }^{14} \mathrm{C}\right] \text { casein } \\
\text { degraded }\end{array}$} & \multicolumn{6}{|c|}{ Rate of MNA or $p$-nitroanilide release ( $\mathrm{nmol} \mathrm{mg} \mathrm{of} \mathrm{protein}{ }^{-1} \min ^{-1}$ ) } \\
\hline & & & GlyArg-MNA & ArgArg-MNA & GlyPro-MNA & LeuVal-MNA & LysAla-MNA & $\mathrm{Ala}_{2}-\mathrm{pNA}$ \\
\hline \multirow[t]{12}{*}{ P. ruminicola } & $23^{\mathrm{T}}$ & 11.3 & 5.2 & 2.0 & 24.7 & 0 & 17.0 & 12.5 \\
\hline & $118 \mathrm{~B}$ & 23.2 & 11.7 & 24.1 & 9.6 & 0.8 & 26.8 & 18.2 \\
\hline & TC18 & 33.8 & 9.1 & 5.2 & 7.2 & 5.3 & 4.6 & 18.1 \\
\hline & TC35 & 23.4 & 9.6 & 7.3 & 7.3 & 3.5 & 7.5 & 12.0 \\
\hline & TC44 & 20.8 & 4.7 & 13.1 & 7.9 & 1.9 & 14.6 & 14.7 \\
\hline & TC27 & 16.6 & & & & & & \\
\hline & TS4-6 & 21.1 & & & & & & \\
\hline & TF1-10 & 17.3 & & & & & & \\
\hline & TF1-5 & 14.6 & 2.9 & 1.3 & 2.5 & 0.6 & 2.4 & 7.6 \\
\hline & TF1-2 & 17.9 & & & & & & \\
\hline & TC2-3 & 7.8 & 0.6 & 4.8 & 0.8 & 0.3 & 22.8 & 8.9 \\
\hline & TS1-2 & 15.5 & 3.0 & 13.1 & 7.1 & 2.9 & 12.4 & 18.3 \\
\hline \multirow[t]{4}{*}{ P. ruminicola-like ${ }^{b}$} & TC2-24 & 8.4 & & & & & & \\
\hline & TF2-5 & 62.9 & & & & & & \\
\hline & TC2-28 & 34.7 & & & & & & \\
\hline & 223/M2/7A & 2.8 & & & & & & \\
\hline \multirow[t]{3}{*}{ P. albensis } & M384 ${ }^{\mathrm{T}}$ & 4.1 & 10.6 & 5.1 & 6.5 & 0.9 & 7.5 & 11.4 \\
\hline & $52 / 3$ & & 7.2 & 6.0 & 6.8 & 1.7 & 7.9 & 14.6 \\
\hline & $79 / 1$ & & 7.0 & 6.6 & 7.9 & 1.3 & 8.9 & 13.0 \\
\hline \multirow[t]{4}{*}{ P. brevis } & GA $33^{\mathrm{T}}$ & 25.7 & 0.1 & 1.1 & 16.0 & 3.8 & 15.7 & 23.6 \\
\hline & FC2 & 65.5 & 3.7 & 2.3 & 11.7 & 0.9 & 14.1 & 13.4 \\
\hline & $\mathrm{FC} 4$ & 43.2 & 0.3 & 1.9 & 8.0 & 0.9 & 12.4 & 11.1 \\
\hline & FC6 & 40.2 & 0.0 & 0.0 & 24.8 & 0.0 & 31.3 & 16.4 \\
\hline \multirow[t]{2}{*}{ P. brevis-like ${ }^{b}$} & TS2-7 & 35.4 & 2.9 & 8.8 & 1.9 & 0.0 & 18.3 & 18.1 \\
\hline & 9958/78 & 37.2 & & & & & & \\
\hline \multirow[t]{5}{*}{ P. bryantii } & $\mathrm{B}_{1} 4^{\mathrm{T}}$ & 8.0 & 3.3 & 1.5 & 3.7 & 0.9 & 3.3 & 13.4 \\
\hline & TC1-1 & 12.7 & 2.5 & 1.3 & 3.8 & 0.9 & 3.9 & 12.2 \\
\hline & TF1-3 & 18.0 & 6.3 & 3.0 & 4.4 & 0.9 & 3.7 & 11.7 \\
\hline & TS1-5 & 9.3 & 5.1 & 2.0 & 6.2 & 0.9 & 6.0 & 14.1 \\
\hline & $92 / 2$ & & 1.6 & 0.4 & 3.1 & 0.3 & 3.4 & 11.6 \\
\hline
\end{tabular}

\footnotetext{
${ }^{a}$ The results are the means of the values obtained from two cultures of each strain.
}

${ }^{b}$ These organisms are not recognized by the relevant signature oligonucleotide (2) and exhibit significant genetic divergence from the type strains (see text).

mol\%. Most strains produce abundant extracellular DNase activity, do not exhibit CMCase activity in plate tests, and do not ferment xylose, salicin, arbutin, and rhamnose but do ferment $\mathrm{N}$-acetylglucosamine. Many strains can grow with gum arabic as an energy source. Like $P$. bryantii, P. brevis strains often have coccoid to oval cell morphology $(4,13)$.

Description of Prevotella bryantii sp. nov. Prevotella bryantii (bry.an'ti.i. L. gen. n. bryantii, of Bryant, named after Marvin Bryant, an American microbiologist). A complete description of Prevotella ruminicola subsp. brevis (formerly Bacteroides ruminicola subsp. brevis) biovar 3 (which includes type strain $B_{1} 4$ ) was given by Holdeman et al. (13). This new species includes strains that resemble strain $\mathrm{B}_{1} 4^{\mathrm{T}}$ and have DNA G+C contents between 39 and $43 \mathrm{~mol} \%$. Most strains give clear zones on CMC-containing plates, produce abundant extracellular DNase, and ferment xylose, salicin, arbutin, rhamnose, and inulin but do not ferment $N$-acetylglucosamine. The type strain is strain DSM 11371.

\section{ACKNOWLEDGMENTS}

This work was supported by the Scottish Office Agriculture, Environment and Fisheries Department.

We thank Jennifer Martin and Nest McKain for their contributions to aspects of this work.

\section{REFERENCES}

1. Avguštin, G. 1992. Analysis of the role of Prevotella (Bacteroides) ruminicola in the rumen ecosystem using molecular genetic techniques. Ph.D. thesis University of Ljubljana, Domzale, Slovenia.

2. Avguštin, G., F. Wright, and H. J. Flint. 1994. Genetic diversity and phylogenetic relationships among strains of Prevotella (Bacteroides) ruminicola from the rumen. Int. J. Syst. Bacteriol. 44:246-255.

3. Bryant, M. P. 1972. Commentary on the Hungate technique for culture of anaerobic bacteria. Am. J. Clin. Nutr. 25:1324-1328.

4. Bryant, M. P., N. Small, C. Bouma, and H. Chu. 1958. Bacteroides ruminicola n. sp. and Succinimonas amylolytica, the new genus and species. J. Bacteriol. 76:15-23.

5. Caldwell, D. R., and M. P. Bryant. 1966. Medium without rumen fluid for non-selective enumeration and isolation of rumen bacteria. Appl. Microbiol. 14:794-801.

6. Dehority, B. A. 1966. Characterization of several bovine rumen bacteria isolated with a xylan medium. J. Bacteriol. 91:1724-1729.

7. Dehority, B. A. 1969 . Pectin-fermenting bacteria isolated from the bovine rumen. J. Bacteriol. 99:189-196.

8. Flint, H. J., and A. M. Thomson. 1990. Deoxyribonuclease activity in isolated rumen bacteria. Lett. Appl. Microbiol. 11:18-21.

9. Gardner, R. G., J. E. Wells, J. B. Russell, and D. B. Wilson. 1995. The cellular location of Prevotella numinicola $\beta-1,4-\mathrm{D}-\mathrm{D}$ doglucanase and its occurrence in other strains of ruminal bacteria. Appl. Environ. Microbiol. 61:3288-3292.

10. Hespell, R. B., and T. R. Whitehead. 1990. Physiology and genetics of xylan degradation by gastrointestinal tract bacteria. J. Dairy Sci. 73:3013-3022

11. Hobson, P. N. 1969. Rumen bacteria. Methods Microbiol. 3B:133-149.

12. Holdeman, L. V., I. J. Good, and W. E. C. Moore. 1976. Human cecal flora variation in bacterial composition within individuals and a possible effect of emotional stress. Appl. Environ. Microbiol. 31:359-375. 
13. Holdeman, L. V., R. W. Kelley, and W. E. C. Moore. 1984. Bacteroides, p. 623-624. In N. R. Krieg and J. G. Holt (ed.), Bergey's manual of systematic bacteriology, vol. 1. Williams and Wilkins, Baltimore, Md.

14. Hungate, R. E. 1966. The rumen and its microbes. Academic Press, Inc., New York, N.Y.

15. Mannarelli, B. M., L. D. Ericsson, D. Lee, and R. J. Stack. 1991. Taxonomic relationships among strains of the anaerobic bacterium Bacteroides ruminicola determined by DNA and extracellular polysaccharide analysis. Appl Environ. Microbiol. 57:2975-2980.

16. McKain, N., R. J. Wallace, and N. D. Watt. 1992. Selective isolation of bacteria with dipeptidyl aminopeptidase I activity from the sheep rumen. FEMS Microbiol. Lett. 95:169-174.

17. Pittman, K. A., and M. P. Bryant. 1964. Peptides and other nitrogen sources for growth of Bacteroides ruminicola. J. Bacteriol. 88:401-410.

18. Robinson, I. M., M. J. Allison, and A. J. Bucklin. 1981. Characterization of the cecal bacteria of normal pigs. Appl. Environ. Microbiol. 41:950-955.

19. Robinson, I. M., S. C. Whipp, A. J. Bucklin, and M. J. Allison. 1984 Characterization of predominant bacteria from the colons of normal and dysenteric pigs. Appl. Environ. Microbiol. 48:964-969.

20. Rudek, W., and R.-U. Haque. 1976. Extracellular enzymes of the genus Bacteroides. J. Clin. Microbiol. 4:458-460.

21. Russell, J. B. 1983. Fermentation of peptides by Bacteroides ruminicola $\mathrm{B}_{1} 4$ Appl. Environ. Microbiol. 45:1568-1574.
22. Shah, H. N., and M. D. Collins. 1990. Prevotella, a new genus to include Bacteroides melaninogenicus and related species formerly classified in the genus Bacteroides. Int. J. Syst. Bacteriol. 40:205-208.

23. Teather, R. M., and P. J. Wood. 1982. Use of Congo red-polysaccharide interactions in enumeration and characterization of cellulolytic bacteria from the bovine rumen. Appl. Environ. Microbiol, 43:777-780.

24. Thomson, A. M. 1990 . Gene transfer in rumen Bacteroides species. Ph.D. thesis. University of Aberdeen, Aberdeen, United Kingdom.

25. Van Gylswyk, N. O. 1990. Enumeration and presumptive identification of some functional groups of bacteria in the rumen of dairy cows fed grass silage-based diets. FEMS Microbiol. Ecol. 73:243-254.

26. Wallace, R. J., and M. L. Brammall. 1985. The role of different species of bacteria in the hydrolysis of protein in the rumen. J. Gen. Microbiol. 131: $821-832$.

27. Wallace, R. J., and N. McKain. 1989. Analysis of peptide metabolism by ruminal microorganisms. Appl. Environ. Microbiol. 55:2372-2376.

28. Wallace, R. J., and N. McKain. 1991. A survey of peptidase activity in rumen bacteria. J. Gen. Microbiol. 137:2259-2264.

29. Wallace, R. J., N. McKain, and G. A. Broderick. 1993. A comparison of the breakdown of pure peptides by Bacteroides ruminicola and mixed rumen microorganisms from the sheep rumen. Curr. Microbiol. 26:333-336.

30. Wood, J., and H. J. Flint. Unpublished data. 